University of Massachusetts Amherst

ScholarWorks@UMass Amherst

Chemistry Department Faculty Publication Series

Chemistry

2000

\title{
Determination of trace elements in marine plankton by inductively coupled plasma mass spectrometry (ICP-MS)
}

Z Arslan

NErtas

JF Tyson

PC Uden

ER Denoyer

Follow this and additional works at: https://scholarworks.umass.edu/chem_faculty_pubs

Part of the Chemistry Commons

\section{Recommended Citation}

Arslan, Z; Ertas, N; Tyson, JF; Uden, PC; and Denoyer, ER, "Determination of trace elements in marine plankton by inductively coupled plasma mass spectrometry (ICP-MS)" (2000). Fresenius Journal of Analytical Chemistry. 1048.

Retrieved from https://scholarworks.umass.edu/chem_faculty_pubs/1048 


\section{Determination of trace elements in marine plankton by inductively coupled plasma mass spectrometry (ICP-MS)}

Received: 16 July 1999 / Revised: 13 September 1999 / Accepted: 14 September 1999

\begin{abstract}
A method has been developed for the determination of 23 elements in marine plankton in which inductively coupled plasma (ICP) source mass spectrometry (MS) was used to quantify the elements in the solution after digestion in a mixture of hydrofluoric and nitric acids in sealed PTFE vessels in a microwave field. The procedure was validated by the analysis of a standard reference soil (SRM 2709 San Joaquin Soil) and a standard reference fresh water plankton (CRM 414). The method was applied to the analysis of several marine plankton samples grown under controlled conditions including several whose growth media had been enriched with selenium. Matrix induced signal suppressions and instrumental drift were corrected by internal standardization. The suitabilities of germanium, indium, rhodium, scandium and yttrium as internal standard elements were evaluated. Neither scandium nor yttrium could be used due to the presence of these elements in the samples, germanium was used for the determination of $\mathrm{As}, \mathrm{Co}, \mathrm{Cu}, \mathrm{Fe}, \mathrm{Ni}, \mathrm{Se}, \mathrm{Si}$ and $\mathrm{Zn}$, indium was used for $\mathrm{Al}, \mathrm{Ba}, \mathrm{Ca}, \mathrm{Eu}, \mathrm{Sr}$, and Tl, and rhodium was used for $\mathrm{Cd}, \mathrm{Cr}, \mathrm{Hg}, \mathrm{Mg}, \mathrm{Pb}, \mathrm{Sb}, \mathrm{Sn}$, and $\mathrm{V}$. For $\mathrm{Al}, \mathrm{Ca}, \mathrm{Cr}, \mathrm{Cu}$, $\mathrm{Fe}, \mathrm{Mg}, \mathrm{Mn}, \mathrm{Ni}, \mathrm{Si}, \mathrm{Sr}, \mathrm{V}$, and $\mathrm{Zn}$ internal standardization did not completely compensate for the suppressive effect of the heavier elements and the solutions were diluted. However, for As, Ba, Cd, Co, Eu, $\mathrm{Hg}, \mathrm{Pb}, \mathrm{Sb}, \mathrm{Se}, \mathrm{Sn}$ and $\mathrm{Tl}$, it was possible to obtain accurate results despite the 35-
\end{abstract}

\author{
Z. Arslan · J. F. Tyson (凶) • P. C. Uden \\ Department of Chemistry, University of Massachusetts, \\ Box 34510, Amherst, Massachusetts, 01003-4510, USA \\ E. R. Denoyer \\ The Perkin Elmer Corporation, 761 Main Avenue, \\ Norwalk, CT 06856, USA \\ N. Ertas \\ Department of Chemistry, The Middle East Technical University, \\ Ankara, Turkey
}

Supplementary material to this paper (Tables 5 and 6) can be obtained electronically using the Springer Link server located at http://link.springer.de/journals/fjac
$40 \%$ suppression in the signals. Isobaric overlap was only a problem in the cases of ${ }^{42} \mathrm{Ca}$ and ${ }^{78} \mathrm{Se} ;{ }^{44} \mathrm{Ca}$ and ${ }^{77} \mathrm{Se}$, respectively, were used. Memory effects were only observed with $\mathrm{Hg}$ for which a nitric acid-sodium chloride solution was the most effective wash-out solution. The marine plankton samples were able to tolerate a higher concentration of $\mathrm{Hg}$ as the selenium concentration increased.

\section{Introduction}

Plankton are the passively drifting, mostly unattached plants (phytoplankton) and unicellular animals (zooplankton) in the marine environment $[1,2]$. In addition to the various macro- and micro-nutrients, seawater contains nonessential or toxic metals (e.g. $\mathrm{Hg}, \mathrm{Cd}, \mathrm{Pb}$, and $\mathrm{As}$ ) originating from weathering, leaching and from anthropogenic sources $[3,4]$. These metals may be taken up by phytoplankton and either (a) cycled within the marine environment or (b) assimilated by a consumer and transferred into the marine food web [5]. The uptake by plankton is an important route for the introduction of essential and toxic metals into the marine food web. Phytoplankton have been used to investigate pollution [6].

An understanding of this bioaccumulation is still in its infancy since there are very few data concerning metal concentrations in pure samples of plankton $[6,7]$ because of the difficulties of measuring reliably very low concentrations of metals in small samples. The most definitive analytical results are those of Quevauviller et al. [6] who reported on a collaborative study by a number of European laboratories to produce a fresh water plankton Certified Reference Material (CRM 414). The material was certified for As, $\mathrm{Cd}, \mathrm{Cr}, \mathrm{Cu}, \mathrm{Hg}, \mathrm{Mn}, \mathrm{Ni}, \mathrm{Pb}, \mathrm{Se}, \mathrm{V}$, and $\mathrm{Zn}$, and indicative values for other 24 elements were also provided. A number of analytical techniques were used.

Inductively coupled plasma mass spectrometry (ICPMS) has become an attractive analytical technique for trace element determinations [8-10]. The major advantages of ICP-MS are well documented [9-13]. Numerous determinations of trace elements in biological materials [10, 11, 
13], foods [14, 15], siliceous materials [12, 16, 17], and saline solutions [18] have been reported. However, ICPMS, does suffer from both spectral and non-spectral interferences $[8,18]$. The spectral interferences are due to spectral overlaps of atomic and molecular ions which have the same nominal $\mathrm{m} / \mathrm{z}$ ratio as the analyte of interest. The atomic interferences can be overcome by utilizing alternative isotopes or by measurements of other isotopes of interfering elements and the use of correction equations for analysis $[8,12,15]$. The polyatomic-ion interferences due to the plasma and atmospheric gases, acids used in sample dissolution and the sample matrix can be eliminated by alternative sample preparation methods such as precipitation and solvent extraction, on-line separation methods, thermal vaporization and hydride/vapor generation [8], or by the use of a high resolution spectrometer $[13,19]$. Nonspectral interferences, which are usually characterized by a suppression in the analyte signal, are caused by the nature and the concentration of sample matrix and plasma operating conditions. Many of these effects are considered to arise from space-charge effects in the ions lenses $[8,12$, $13,18]$. Internal standardization has been shown to be an effective means of compensating for the matrix induced suppression providing that an internal standard of similar mass and first ionization energy to the analyte is chosen [8-18]. Flow injection techniques have also been successfully utilized with ICP-MS to implement various strategies for overcoming the matrix interferences $[20,21]$.

Plankton is composed of organic matter and a siliceous skeleton [2, 3, 7]. Organic matter is generally decomposed by an oxidation process using strong oxidizing agents. Nitric acid is the preferred agent for ICP-MS determinations, while other acids are avoided to eliminate spectral interferences due to the presence of polyatomic ions containing $\mathrm{Cl}, \mathrm{P}$ and $\mathrm{S}$, respectively $[8,12]$. For the dissolution of silicates, $\mathrm{HF}$ is needed $[8,12,13]$. Closed-vessel digestion is advantageous, not only to reach higher temperatures but also to retain volatile species of elements such as Se and $\mathrm{Hg}[22,23]$. Wu et al. [12] developed a method for the dissolution of soils to determine trace elements by ICPMS. Microwave-assisted digestion was performed with a mixture of $\mathrm{HNO}_{3} / \mathrm{H}_{2} \mathrm{O}_{2} / \mathrm{H}_{3} \mathrm{BO}_{3} / \mathrm{HF}$ acids. Boric acid was added to complex the excess fluoride and to prevent the precipitation of various sparingly soluble fluorides. The polyatomic ion signals from $\mathrm{B}, \mathrm{Ar}, \mathrm{O}$ and $\mathrm{H}$ species on ${ }^{63} \mathrm{Cu}^{+},{ }^{65} \mathrm{Cu}^{+},{ }^{66} \mathrm{Zn}^{+}$and ${ }^{68} \mathrm{Zn}^{+}$were relatively weak. However, strong ion signals were observed from boron oxides on ${ }^{26} \mathrm{Mg}^{+},{ }^{27} \mathrm{Al}^{+}$and ${ }^{43} \mathrm{Ca}^{+}$, from boron hydroxides on ${ }^{27} \mathrm{Al}^{+}$, ${ }^{28} \mathrm{Si}^{+},{ }^{4} \mathrm{Ca}^{+}$and ${ }^{45} \mathrm{Sc}^{+}$, from boron argides at $\mathrm{m} / \mathrm{z} 46-51$, and from boron fluoride at $\mathrm{m} / \mathrm{z} 48,49$. Thus, the detection limits of the affected isotopes were poorer than those obtained from solutions in $1 \% \mathrm{HNO}_{3}$. Uchida et al. [13] reported the determination of trace elements in seaweed reference materials in which samples were digested in PTFE beakers with a $\mathrm{HNO}_{3} / \mathrm{HClO}_{4} / \mathrm{HF}$ mixture. The interference of ${ }^{75} \mathrm{ArCl}^{+}$on ${ }^{75} \mathrm{As}^{+}$was not significant due to the high concentration of As in sea weed samples. In the certification process of a fresh water plankton material for the trace element concentrations, Quevauviller et al. [7] reported that the recoveries for $\mathrm{Cd}, \mathrm{Cr}, \mathrm{Cu}$ and $\mathrm{Pb}$ obtained from a $\mathrm{HNO}_{3}$ digestion were significantly lower than those from $\mathrm{HNO}_{3} / \mathrm{HF}$ due to the incomplete extraction of these elements from the siliceous composition and concluded that closed vessel pressurized digestion with a $\mathrm{HNO}_{3} / \mathrm{HF}$ mixture using microwave heating was necessary for the complete dissolution of the material.

We have developed a method for the determination of trace elements in silicate matrices by ICP-MS in which the sample was dissolved in a mixture of hydrofluoric and nitric acids. Possible polyatomic ion interferences and their effects on the accuracy of the analytical results are discussed. Internal standardization and sample dilution are also investigated for the compensation of the suppression of ion signals in the plasma by the sample matrix. The validated method was then used to determine elemental concentrations of metals in marine plankton.

\section{Experimental}

Instrumentation. A Perkin-Elmer Sciex Elan ${ }^{\circledR} 5000$ ICP-MS (PerkinElmer, Norwalk, CT, USA) equipped with a standard ICP torch, removable alumina injector, cross flow nebulizer, nickel sampler and skimmer cones and four-channel mass flow controller was used. A Gilson Minipuls II peristaltic pump was used for the introduction of standard and sample solutions. The instrument was optimized daily by aspirating a $10 \mu \mathrm{g} / \mathrm{L}$ solution of ${ }^{24} \mathrm{Mg},{ }^{103} \mathrm{Rh}$ and ${ }^{208} \mathrm{~Pb}$ in $1 \% \mathrm{v} / \mathrm{v} \mathrm{HNO}_{3}$ solution. The nebulizer flow rate was changed to obtain the maximum ion signals. No specific corrections were considered for the polyatomic ion interferences, while isotopic overlaps were corrected by the ELAN software. The instrumental parameters are listed in Table 1. For the microwave digestion of the samples, a CEM (Indian Trail, NC, USA) Model MSD-81D microwave oven providing $630 \pm 70 \mathrm{~W}$ output power at $100 \%$ power setting was used. The 12 -vessel turntable drive system rotates the samples $360^{\circ}$ within the microwave field at $6 \mathrm{rpm}$. The vessel body and the cap are made of polyetherimide (Ultem), and the liner, cover and the rupture membrane are made of Teflon ${ }^{\circledR}$-perfluoralkoxy (PFA). The vent screw is constructed of PTFE. The volume of the liner is $100 \mathrm{~mL}$.

Reagents and standard solutions. High-purity deionized distilled water with a resistivity of $18 \mathrm{M} \Omega \mathrm{cm}$ was used to prepare all standard and sample solutions. Double-distilled HF (EM Science, 99.9995\%) and laboratory sub-boiled $\mathrm{HNO}_{3}$ (Fisher) were used for

Table 1 ICP-MS instrumental operating parameters

\begin{tabular}{ll}
\hline Rf power, W & 1000 \\
Plasma gas flow, L/min & 15.0 \\
Nebulizer gas flow, L/min & $0.90-0.96$ \\
Auxiliary gas flow, L/min & 0.80 \\
Nebulizer & Cross flow \\
Spray chamber & Double pass \\
Sample uptake, mL/min & 1 \\
Scanning mode & Peak hop \\
Replicate time, ms & 300 \\
Dwell time, ms & 100 \\
Sweeps/Reading & 3 \\
Readings/Replicate & 1 \\
Number of replicates & 3 \\
Points per spectral peak & 1 \\
Read delay time, s & 35 \\
\hline
\end{tabular}


the digestion of samples. The standard working solutions of $\mathrm{Al}$, As, Ba, Ca, Cd, Co, Cr, Cu, Eu, Fe, $\mathrm{Hg}, \mathrm{Mg}, \mathrm{Mn}, \mathrm{Ni}, \mathrm{Pb}, \mathrm{Sb}, \mathrm{Se}$, $\mathrm{Si}, \mathrm{Sn}, \mathrm{Sr}, \mathrm{Tl}, \mathrm{Zn}$ and $\mathrm{V}$ were prepared from a $10 \mu \mathrm{g} / \mathrm{mL}$ multielement standard stock solution by diluting to $50 \mathrm{~mL}$ with $2 \% \mathrm{HNO}_{3}$ (v/v) solution. To all standard and sample solutions, $250 \mu \mathrm{L}$ of a solution containing $10 \mu \mathrm{g} / \mathrm{mL} \mathrm{Ge}, \mathrm{In}, \mathrm{Rh}, \mathrm{Sc}, \mathrm{Te}$ and $\mathrm{Y}$ as internal standards was added to yield $50 \mu \mathrm{g} / \mathrm{L}$ in the final dilution. Standard and sample solutions were stored in polyethylene bottles which had been soaked in 5\% v/v nitric acid and rinsed with water before use.

Method development. For the digestion of soil samples, the volume of concentrated hydrofluoric acid added was varied from 1 to $12 \mathrm{~mL}$. The applied power of microwave system was varied from 20 to $60 \%$. Memory effects were investigated for all elements by aspirating a standard solution containing $200 \mu \mathrm{g} / \mathrm{L}$ of As, Ba, Cd, Co, $\mathrm{Cr}, \mathrm{Eu}, \mathrm{Hg}, \mathrm{Pb}, \mathrm{Sb}, \mathrm{Se}, \mathrm{Sr}, \mathrm{Sn}, \mathrm{Tl}$ and $\mathrm{V}$ and $2000 \mu \mathrm{g} / \mathrm{L} \mathrm{Al}, \mathrm{Ca}, \mathrm{Cu}$, $\mathrm{Fe}, \mathrm{Mg}, \mathrm{Mn}, \mathrm{Ni}, \mathrm{Si}$ and $\mathrm{Zn}$. Preliminary experiments were performed by assigning two different internal standards for $\mathrm{Cd}, \mathrm{Cr}, \mathrm{Hg}$, $\mathrm{Mg}, \mathrm{Mn}, \mathrm{Sb}$ and $\mathrm{V}$ to investigate the significance of the ionization potential and the mass number of the internal standard element on the correction of the matrix effects. The internal standard was assigned in such a way that it was either similar in first ionization potential or in mass number to that of the analyte. Initial experiments showed that the metal concentrations of the plankton were significantly lower than that of the soil reference material used. Thus, several isotopes of the polyisotopic elements were simultaneously determined in both the original and the diluted solutions to identify the isotope most free from interference and the optimum dilution.

Memory effects due to the (a) deposition on the interface of the spectrometer, (b) deposition on the ion lenses, or (c) retention in the spray chamber and transfer tubing were investigated. The efficiencies of various solutions including mixtures of $\mathrm{HNO}_{3}, \mathrm{HF}$ and $\mathrm{NaCl}$ for the washout mercury were studied. Possible attack of HF on quartz torch was monitored by visual observation of the surface of the torch for deteriorations and evaluating with the accuracy of the values of silicon obtained from the reference soil material.

Method validation. Two reference materials, SRM 2709 San Joaquin Soil (NIST) and CRM 414 Fresh Water Plankton (BCR), were used for the method validation, and 4 replicate analyses were made for each reference material. Calibration was performed with nine aqueous standards and a blank. The multielement standards were 0.2 , $0.5,1.0,2.0,5.0,10.0,20.0,50.0,100$ and $200 \mu \mathrm{g} / \mathrm{L}$ for As, Ba, $\mathrm{Cd}, \mathrm{Co}, \mathrm{Cr}, \mathrm{Eu}, \mathrm{Hg}, \mathrm{Pb}, \mathrm{Sb}, \mathrm{Se}, \mathrm{Sr}, \mathrm{Sn}, \mathrm{Tl}$ and $\mathrm{V}$ and 2.0, 5.0, 10.0, $20.0,50.0,100,200,500,1000$ and $2000 \mu \mathrm{g} / \mathrm{L}$ for $\mathrm{Al}, \mathrm{Ca}, \mathrm{Cu}, \mathrm{Fe}$, $\mathrm{Mg}, \mathrm{Mn}, \mathrm{Ni}, \mathrm{Si}$ and $\mathrm{Zn}$. Three replicate measurements were made for each solution. The blank subtractions and the calculations of standard counts/internal standard counts ratios (Std/IntStd) were made by the ELAN software (Version 2.2). The calibration data for each isotope was further processed on a personal computer using a graphics software package (Cricket Graph Version 1.3.2) to construct the calibration curve and to obtain the equation of calibration. The Std/IntStd of six standards bracketing that of the sample were used to construct the calibration curve. Visual inspection of all scatter plots indicated that the external calibration plots were linear over the concentration range used. Correlation coefficients (r) ranged from 0.997 to 1.00 . To calculate the concentration of each analyte, the sample counts/internal standard counts ratios (Smp/ IntStd) of the analysis solutions were substituted into the appropriate calibration equation.

Samples. Freeze-dried plankton samples $(3 \mathrm{H})$ were provided by the National Marine Fisheries Service (NMFS) Laboratory, Milford, CT. The particular plankton samples were artificially grown in a simulated seawater under the following controlled concentrations of trace metal nutrient, $\mathrm{Sr} 30 \mathrm{mg} / \mathrm{L}, \mathrm{Al} 10 \mathrm{mg} / \mathrm{L}, \mathrm{As}, \mathrm{Cd}, \mathrm{Pb}, \mathrm{Hg}$, $\mathrm{Sn}, \mathrm{Tl}$ and $\mathrm{Eu} 0.5 \mathrm{mg} / \mathrm{L}$. The predicted elemental concentrations, assuming all the elements to be consumed during the growth, would be $\mathrm{Sr} 150 \mu \mathrm{g} / \mathrm{g}, \mathrm{Al} 50 \mu \mathrm{g} / \mathrm{g}$, As, Cd, Pb, Hg, Sn, Tl and Eu $2.5 \mu \mathrm{g} / \mathrm{g}$ on a dry basis.

A second set of plankton samples $(3 \mathrm{H})$ were grown with identical trace element concentrations, but enriched with different con- centrations of $\mathrm{Se}$ as an additional nutrient element to investigate the effect of Se on plankton growth. The concentrations of Se added to the growth medium were as follows: $130 \mathrm{mg} / \mathrm{L}$ for $3 / 27 / 97$ and 4/10/ 97 plankton samples, $13 \mathrm{mg} / \mathrm{L}$ for 5/1/97 and 5/8/97 plankton samples, and $1.3 \mathrm{mg} / \mathrm{L}$ for $6 / 5 / 97,6 / 12 / 97$ and 6/19/97 plankton samples.

Procedure. Microwave-assisted closed vessel digestion was performed for the dissolution of the soil and plankton samples [24]. Approximately $100 \mathrm{mg}$ of sample for soil or $200 \mathrm{mg}$ for fresh water plankton, $3 \mathrm{~mL}$ concentrated sub-boiled $\mathrm{HNO}_{3}$ and $1.5 \mathrm{~mL}$ concentrated HF were placed into the Teflon ${ }^{\circledR}$-PFA vessels of the microwave digestion system. A reagent blank was also prepared with $3 \mathrm{~mL} \mathrm{HNO}_{3}$ and $1.5 \mathrm{~mL} \mathrm{HF}$. Five vessels were tightly capped and irradiated at $40 \%$ power for $10 \mathrm{~min}$ with continuous monitoring. At the end of the program, the vessels were removed and cooled to room temperature in a fume hood and the pressure inside the vessels slowly released. After re-tightening, the vessels were irradiated for a further $10 \mathrm{~min}$. This step was repeated. At the end of the third period, the vessels were cooled to room temperature and opened to check if the complete dissolution, yielding colorless solutions, had occurred. In the cases of incomplete dissolution, the microwave program was continued until the sample had dissolved After cooling, the contents to which $250 \mu \mathrm{L}$ of $10 \mu \mathrm{g} / \mathrm{mL}$ internal standard solution had been added, were diluted to $50 \mathrm{~mL}$ in a calibrated polyethylene flask with deionized water. The resulting solution contained approximately $6 \% \mathrm{v} / \mathrm{v} \mathrm{HNO}_{3}$, approximately $3 \%$ $\mathrm{v} / \mathrm{v} \mathrm{HF}$ and $50 \mu \mathrm{g} / \mathrm{L}$ of $\mathrm{Ge}, \mathrm{In}, \mathrm{Rh}, \mathrm{Sc}, \mathrm{Te}$ and $\mathrm{Y}$ as internal standards.

For the digestion of the $3 \mathrm{H}$ plankton samples, approximately $400 \mathrm{mg}$ of sample and the same volumes of $\mathrm{HF}$ and $\mathrm{HNO}_{3}$ as for the soil and fresh water plankton were placed into Teflon ${ }^{\circledR}$-PFA vessels. The digestion program, dilutions and internal standard additions were also performed as for the soil and the fresh water plankton.

\section{Results and discussion}

\section{The digestion parameters}

The certified concentration of Si in SRM 2709 is $29.66 \%$, which was initially assumed to be far greater than that in plankton. The volume of $49 \% \mathrm{~m} / \mathrm{v}$ HF required for the complete dissolution of silicon dioxide present in $1 \mathrm{~g} \mathrm{sam}$ ple, according to the equation $\mathrm{SiO}_{2}+6 \mathrm{HF} \rightarrow \mathrm{H}_{2} \mathrm{SiF}_{6}+$ $2 \mathrm{H}_{2} \mathrm{O}$, is $4 \mathrm{~mL}$. An excess of HF is necessary in the digestion medium, because the reaction of $\mathrm{HF}$ with $\mathrm{SiO}_{2}$ in a mixture of acids is slower than that of pure HF [24]. It was found that $1 \mathrm{~mL}$ of concentrated HF was sufficient to dissolve the soil samples. However, $1.5 \mathrm{~mL}$ was added to both soil and plankton samples to avoid any possible incomplete dissolution. The optimum power for the microwave oven was $40 \%$, which gave an approximate digestion time of $1 \mathrm{~h}$ At lower power settings, not only did the digestion take longer, but some samples did not completely dissolve. A rapid increase in pressure inside the vessels occurred at higher power settings. These settings were not used for safety reasons.

It has been reported that a mixture of $\mathrm{HNO}_{3} / \mathrm{HF}$ can readily dissolve silicates without further addition of strong oxidants such as $\mathrm{H}_{2} \mathrm{O}_{2}$ and $\mathrm{HClO}_{4}[25,26]$. This minimizes the reagent contamination in trace element determinations. In addition, no deterioration of the inner surface of the quartz torch was observed due to the direct aspiration of the solutions containing 3\% v/v HF. The results for $\mathrm{Si}$ (Table 3) also support this observation, in that there was 


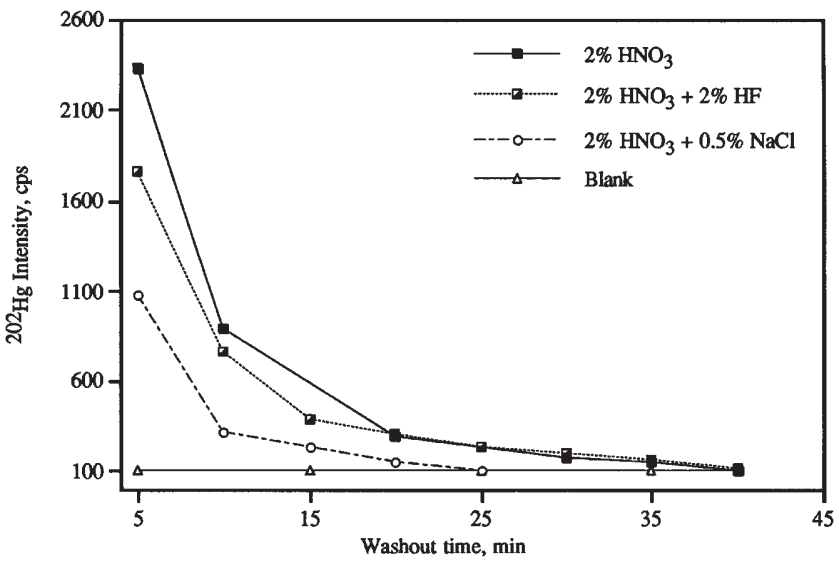

Fig. 1 Effect of various solutions on residual $\mathrm{Hg}$ washout as a function of time

no significant $\mathrm{Si}$ contribution from the torch. Thus, it was not necessary to complex excess fluoride with $\mathrm{H}_{3} \mathrm{BO}_{3}$ which can cause polyatomic intereferences due to $\mathrm{B}$ as reported by Wu et al. [12].

\section{Memory effects}

No memory effects were observed for the elements determined, except in the case of $\mathrm{Hg}$, after aspirating the multielement test solution. Other residual elements were completely cleaned from the interface of the spectrometer in a 2 -min rinsing time with $2 \% \mathrm{v} / \mathrm{v} \mathrm{HNO}_{3}$. Of the solutions used to remove deposited $\mathrm{Hg}, 0.5 \% \mathrm{~m} / \mathrm{v} \mathrm{NaCl}+2 \% \mathrm{v} / \mathrm{v}$ $\mathrm{HNO}_{3}$ solution was the most effective. This was attributed to the increased salt content of the cleaning solution (Fig. 1). This result also indicated that deposition of $\mathrm{Hg}$ occurred on the interface such as injector and sampling cones rather than the mass detection system of the instrument.

\section{Comparison of internal standards}

Antimony, $\mathrm{Cd}, \mathrm{Cr}, \mathrm{Mg}, \mathrm{Mn}, \mathrm{Hg}$, and $\mathrm{V}$ were selected to investigate the influence of the internal standard element on the accuracy of the analysis in the presence of matrix in- duced suppression and instrumental sensitivity changes. Germanium $\left({ }^{72} \mathrm{Ge}\right)$ and ${ }^{103} \mathrm{Rh}$, which have similar first ionization potentials (IP), but different atomic masses, were used for ${ }^{111} \mathrm{Cd},{ }^{25} \mathrm{Mg},{ }^{55} \mathrm{Mn}$ and ${ }^{123} \mathrm{Sb}$ to investigate the significance of mass number. To investigate the effect of IP, ${ }^{103} \mathrm{Rh}$ and ${ }^{126} \mathrm{Te}$, and ${ }^{115} \mathrm{In}$ and ${ }^{103} \mathrm{Rh}$ pairs with similar masses but different first IPs were used for ${ }^{202} \mathrm{Hg}$, and ${ }^{53} \mathrm{Cr}$ and ${ }^{51} \mathrm{~V}$, respectively. The results are listed in Table 2. There was no significant difference between the results for $\mathrm{Cd}$, $\mathrm{Mg}, \mathrm{Mn}$ and $\mathrm{Sb}$ obtained with ${ }^{72} \mathrm{Ge}$ and ${ }^{103} \mathrm{Rh}$, which also agreed with the certified values. For $\mathrm{Hg},{ }^{126} \mathrm{Te}$ provided a better result than that obtained with ${ }^{103} \mathrm{Rh}$; the recoveries were 106 and $115 \%$, respectively. Similar results were also found for $\mathrm{Cr}$ and $\mathrm{V}$. These results indicate that ${ }^{103} \mathrm{Rh}$ can be used as an internal standard for these elements. Additional studies were performed for ${ }^{25} \mathrm{Mg},{ }^{53} \mathrm{Cr}$ and ${ }^{51} \mathrm{~V}$ with ${ }^{89} \mathrm{Y}(6.38 \mathrm{eV})$ and ${ }^{45} \mathrm{Sc}(6.54 \mathrm{eV})$ as internal standards. However, the recoveries were low, varying between 80 $87 \%$. This was due to the presence of $\mathrm{Y}$ and Sc in the samples, which resulted in higher $\mathrm{Y}$ and Sc counts and consequently decreased the Smp/IntStd ratios. This indicates that Y and Sc may not be suitable for internal standardization since they can be present in various matrices at high concentrations.

The effect of matrix dilution, interferences and internal standardization

One type of matrix suppression of ion signals in ICP-MS is referred to as the "space-charge effect" where the ion beam is disturbed in the path through the ion optics and mass spectrometer, and the magnitude of the suppression can be significantly reduced by diluting the sample solution $[8,13]$. The major source of such a non-spectroscopic interference is considered to be $\mathrm{Si}$ whose concentration in the original $50-\mathrm{mL}$ soil solution was $600-650 \mu \mathrm{g} / \mathrm{mL}$, when 100-110 mg of sample was dissolved and diluted. Further, semi-quantitative analyses performed on plankton samples by ICP-MS revealed that the concentrations of all elements except $\mathrm{Si}$ were significantly lower than those in SRM 2709, which consequently limited higher dilution of plankton solutions. Thus, the soil solutions obtained from microwave digestion were analyzed in the original (i.e.
Table 2 The effect of internal standards for the accurate correction of matrix effects

Results are given as mean \pm $95 \%$ confidence interval for 4 separate analyses

Certified values are given as mean $\pm 95 \%$ confidence interval

a Values are given as $\% \mathrm{~m} / \mathrm{m}$ - Not studied
Isotope IP, eV Experimental results, $\mu \mathrm{g} / \mathrm{g}$ Internal standards

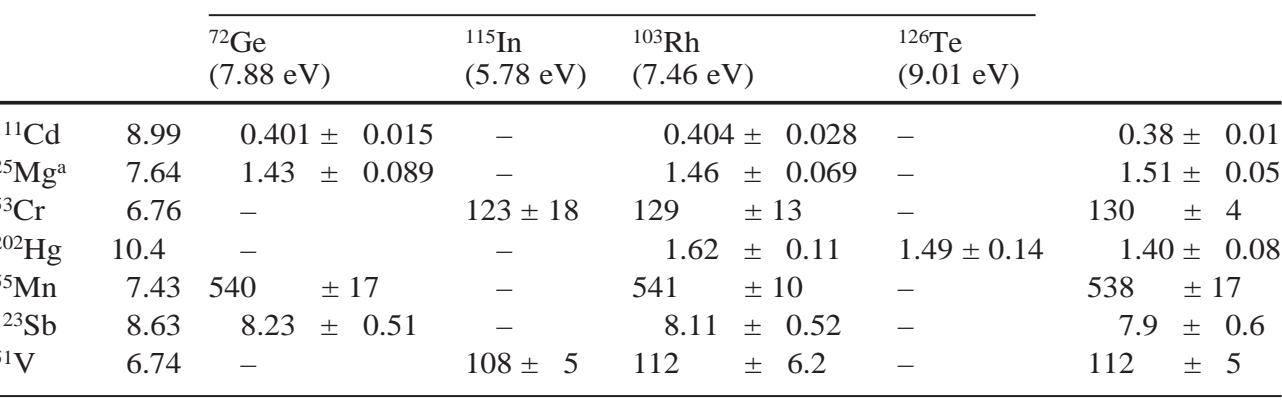

\begin{tabular}{|c|c|c|c|c|c|c|}
\hline & & & \\
\hline & & $\begin{array}{l}{ }^{72} \mathrm{Ge} \\
(7.88 \mathrm{eV})\end{array}$ & $\begin{array}{l}{ }^{115} \mathrm{In} \\
(5.78 \mathrm{eV})\end{array}$ & $\begin{array}{l}{ }^{103} \mathrm{Rh} \\
(7.46 \mathrm{eV})\end{array}$ & $\begin{array}{l}{ }^{126} \mathrm{Te} \\
(9.01 \mathrm{eV})\end{array}$ & \\
\hline${ }^{111} \mathrm{Cd}$ & 8.99 & $0.401 \pm 0.015$ & - & $0.404 \pm 0.028$ & - & $0.38 \pm 0.01$ \\
\hline${ }^{25} \mathrm{Mg}^{\mathrm{a}}$ & 7.64 & $1.43 \pm 0.089$ & - & $1.46 \pm 0.069$ & - & $1.51 \pm 0.05$ \\
\hline${ }^{53} \mathrm{Cr}$ & 6.76 & - & $123 \pm 18$ & $129 \pm 13$ & - & $130 \pm 4$ \\
\hline${ }^{202} \mathrm{Hg}$ & 10.4 & - & - & $1.62 \pm 0.11$ & $1.49 \pm 0.14$ & $1.40 \pm 0.08$ \\
\hline${ }^{55} \mathrm{Mn}$ & 7.43 & \pm 17 & - & $541 \pm 10$ & - & $538 \pm 17$ \\
\hline${ }^{123} \mathrm{Sb}$ & 8.63 & $8.23 \pm 0.51$ & - & $8.11 \pm 0.52$ & - & $7.9 \pm 0.6$ \\
\hline${ }^{51} \mathrm{~V}$ & 6.74 & - & $108 \pm 5$ & $112 \pm 6.2$ & - & $112 \pm 5$ \\
\hline
\end{tabular}

Cert. Value $\mu \mathrm{g} / \mathrm{g}$ 
Table 3 Results for SRM 2709 (San Joaquin Soil) obtained with different dilutions and instrumental detection limits obtained from 6\% v/v $\mathrm{HNO}_{3} / 3 \%$ v/v HF blank solution

\begin{tabular}{|c|c|c|c|c|c|c|c|c|c|c|c|c|}
\hline \multirow{3}{*}{$\begin{array}{l}\text { Ele- } \\
\text { ment }\end{array}$} & \multirow{3}{*}{$\begin{array}{l}\begin{array}{l}\text { Iso- } \\
\text { tope }\end{array} \\
27\end{array}$} & \multirow{3}{*}{$\begin{array}{l}\text { Internal } \\
\text { Standard } \\
{ }^{115} \mathrm{In}\end{array}$} & \multicolumn{6}{|c|}{ Experimental results $(\mu \mathrm{g} / \mathrm{g})$} & \multirow{2}{*}{\multicolumn{2}{|c|}{$\begin{array}{l}\text { Certified } \\
(\mu \mathrm{g} / \mathrm{g})\end{array}$}} & \multirow{3}{*}{$\begin{array}{l}\begin{array}{l}\text { Blank signal } \\
\text { (Counts/s) }\end{array} \\
1590\end{array}$} & \multirow{3}{*}{$\begin{array}{l}\begin{array}{l}\text { Det. Limit } \\
(\mu \mathrm{g} / \mathrm{L})\end{array} \\
0.27\end{array}$} \\
\hline & & & \multicolumn{2}{|c|}{ No dilution } & \multicolumn{2}{|c|}{$10 \times$ dilute } & \multicolumn{2}{|c|}{$50 \times$ dilute } & & & & \\
\hline & & & $\gg$ & & 5.97 & \pm 0.72 & 7.29 & \pm 0.71 & $7.50 \pm$ & \pm 0.06 & & \\
\hline As & 75 & ${ }^{72} \mathrm{Ge}$ & 16.8 & \pm 0.45 & 18.1 & \pm 0.63 & 13.7 & \pm 1.4 & $17.7 \pm$ & \pm 0.8 & 332 & 0.049 \\
\hline $\mathrm{Ba}$ & 137 & ${ }^{115} \mathrm{In}$ & 884 & \pm 27 & 895 & \pm 12 & 929 & \pm 66 & $968 \pm$ & \pm 40 & 15 & 0.068 \\
\hline $\mathrm{Ba}$ & 138 & ${ }^{115} \mathrm{In}$ & $888=$ & \pm 23 & 897 & \pm 19 & 934 & \pm 53 & $968 \pm$ & \pm 40 & 65 & 0.029 \\
\hline $\mathrm{Ca}^{\mathrm{a}}$ & 42 & ${ }^{115} \mathrm{In}$ & $0.937=$ & \pm 0.117 & 1.56 & \pm 0.25 & 1.45 & \pm 0.21 & $1.89 \pm$ & \pm 0.05 & 17237 & 26 \\
\hline $\mathrm{Ca}^{\mathrm{a}}$ & 44 & ${ }^{115} \mathrm{In}$ & $1.09=$ & \pm 0.089 & 1.82 & \pm 0.14 & 1.97 & \pm 0.13 & $1.89 \pm$ & \pm 0.05 & 1571 & 2.5 \\
\hline $\mathrm{Cd}$ & 111 & ${ }^{103} \mathrm{Rh}$ & $0.404=$ & \pm 0.028 & - & & - & & $0.38 \pm$ & \pm 0.01 & 14 & 0.078 \\
\hline $\mathrm{Cd}$ & 114 & ${ }^{103} \mathrm{Rh}$ & $0.448=$ & \pm 0.158 & - & & - & & $0.38 \pm$ & \pm 0.01 & 22 & 0.042 \\
\hline $\mathrm{Co}$ & 59 & ${ }^{72} \mathrm{Ge}$ & $11.8=$ & \pm 1.5 & 12.6 & \pm 0.75 & 12.7 & \pm 2.1 & $13.4 \pm$ & \pm 0.7 & 86 & 0.028 \\
\hline $\mathrm{Cr}$ & 52 & ${ }^{103} \mathrm{Rh}$ & 78.3 & \pm 5.8 & 109 & \pm 4.8 & 117 & \pm 12 & $130 \pm$ & \pm 4 & 1392 & 0.30 \\
\hline $\mathrm{Cr}$ & 53 & ${ }^{103} \mathrm{Rh}$ & 86.8 & \pm 6.8 & 114 & \pm 7.2 & 129 & \pm 13 & 130 & \pm 4 & 88 & 0.14 \\
\hline $\mathrm{Cu}$ & 63 & ${ }^{72} \mathrm{Ge}$ & 22.8 & \pm 1.5 & 33.8 & \pm 2.5 & 31.1 & \pm 2.7 & $34.6 \pm$ & \pm 0.7 & 1392 & 0.079 \\
\hline $\mathrm{Cu}$ & 65 & ${ }^{72} \mathrm{Ge}$ & 26.9 & \pm 2.3 & 34.9 & \pm 2.1 & 32.4 & \pm 3.2 & $34.6 \pm$ & \pm 0.7 & 88 & 0.036 \\
\hline $\mathrm{Eu}$ & 151 & ${ }^{115} \mathrm{In}$ & 0.953 & \pm 0.021 & 0.854 & \pm 0.122 & - & & $0.9^{\mathrm{b}}$ & & 14 & 0.018 \\
\hline $\mathrm{Eu}$ & 153 & ${ }^{115} \mathrm{In}$ & $0.969=$ & \pm 0.025 & 1.07 & \pm 0.216 & - & & $0.9^{\mathrm{b}}$ & & 12 & 0.014 \\
\hline $\mathrm{Fe}^{\mathrm{a}}$ & 57 & ${ }^{72} \mathrm{Ge}$ & $2.58=$ & \pm 0.16 & 3.34 & \pm 0.094 & 3.46 & \pm 0.16 & $3.50 \pm$ & \pm 0.11 & 760 & 4.1 \\
\hline $\mathrm{Hg}$ & 200 & ${ }^{103} \mathrm{Rh}$ & $1.58=$ & \pm 0.32 & 1.29 & \pm 0.26 & - & & $1.40 \pm$ & \pm 0.08 & 95 & 0.057 \\
\hline $\mathrm{Hg}$ & 202 & ${ }^{103} \mathrm{Rh}$ & $1.62=$ & \pm 0.11 & 1.22 & \pm 0.096 & - & & $1.40 \pm$ & \pm 0.08 & 89 & 0.026 \\
\hline $\mathrm{Mg}^{\mathrm{a}}$ & 25 & ${ }^{103} \mathrm{Rh}$ & $0.632=$ & \pm 0.098 & 1.39 & \pm 0.035 & 1.46 & \pm 0.069 & $1.51 \pm$ & \pm 0.05 & 154 & 0.46 \\
\hline $\mathrm{Mg}^{\mathrm{a}}$ & 26 & ${ }^{103} \mathrm{Rh}$ & $0.638=$ & \pm 0.107 & 1.43 & \pm 0.043 & 1.47 & \pm 0.11 & $1.51 \pm$ & \pm 0.05 & 206 & 0.36 \\
\hline $\mathrm{Mn}$ & 55 & ${ }^{103} \mathrm{Rh}$ & $420=$ & \pm 13 & 541 & \pm 10 & 547 & \pm 26 & $538 \pm$ & \pm 17 & 1093 & 0.035 \\
\hline $\mathrm{Ni}$ & 60 & ${ }^{72} \mathrm{Ge}$ & 59.7 & \pm 1.7 & 78.4 & \pm 4.6 & 75.6 & \pm 2.7 & 88 & \pm 5 & 861 & 0.14 \\
\hline $\mathrm{Ni}$ & 61 & ${ }^{72} \mathrm{Ge}$ & 64.8 & \pm 4.8 & 77.6 & \pm 9.4 & - & & 88 & \pm 5 & 54 & 0.58 \\
\hline $\mathrm{Ni}$ & 62 & ${ }^{72} \mathrm{Ge}$ & 63.7 & \pm 1.8 & 80.3 & \pm 6.4 & 85.7 & \pm 14 & $88 \pm$ & \pm 5 & 136 & 0.42 \\
\hline $\mathrm{Pb}$ & 207 & ${ }^{103} \mathrm{Rh}$ & 20.1 & \pm 1.4 & 18.6 & \pm 1.1 & 19.9 & \pm 2.7 & $18.9 \pm$ & \pm 0.5 & 65 & 0.032 \\
\hline $\mathrm{Pb}$ & 208 & ${ }^{103} \mathrm{Rh}$ & 19.9 & \pm 1.5 & 18.7 & \pm 0.73 & 19.8 & \pm 0.91 & $18.9 \pm$ & \pm 0.5 & 65 & 0.017 \\
\hline $\mathrm{Sb}$ & 121 & ${ }^{103} \mathrm{Rh}$ & 11.4 & \pm 1.2 & 8.01 & \pm 0.25 & - & & $7.9 \pm$ & \pm 0.6 & 287 & 0.054 \\
\hline $\mathrm{Sb}$ & 123 & ${ }^{103} \mathrm{Rh}$ & 11.4 & \pm 1.5 & 8.11 & \pm 0.52 & - & & $7.9 \pm$ & \pm 0.6 & 216 & 0.068 \\
\hline $\mathrm{Se}$ & 77 & ${ }^{72} \mathrm{Ge}$ & $1.44=$ & \pm 0.22 & - & & - & & $1.57 \pm$ & \pm 0.08 & 117 & 1.7 \\
\hline $\mathrm{Se}$ & 78 & ${ }^{72} \mathrm{Ge}$ & $1.28=$ & \pm 0.24 & - & & - & & $1.57 \pm$ & \pm 0.08 & 488 & 1.1 \\
\hline $\mathrm{Se}$ & 82 & ${ }^{72} \mathrm{Ge}$ & $0.577=$ & \pm 0.13 & - & & - & & $1.57 \pm$ & \pm 0.08 & 13 & 1.5 \\
\hline $\mathrm{Si}^{\mathrm{a}}$ & 29 & ${ }^{72} \mathrm{Ge}$ & $12.7=$ & \pm 1.9 & 28.7 & \pm 2.5 & 29.4 & \pm 2.3 & $29.66 \pm$ & \pm 0.23 & 8592 & 20 \\
\hline $\mathrm{Sn}$ & 118 & ${ }^{103} \mathrm{Rh}$ & $2.41=$ & \pm 0.24 & 2.63 & \pm 0.17 & - & & ng & & 88 & 0.035 \\
\hline $\mathrm{Sn}$ & 120 & ${ }^{103} \mathrm{Rh}$ & $2.47=$ & \pm 0.25 & 2.46 & \pm 0.13 & - & & ng & & 115 & 0.038 \\
\hline $\mathrm{Sr}$ & 86 & ${ }^{115} \mathrm{In}$ & $207=$ & \pm 1.8 & 227 & \pm 13 & 224 & \pm 2.6 & 231 & \pm 2 & 20 & 0.086 \\
\hline $\mathrm{Sr}$ & 88 & ${ }^{115} \mathrm{In}$ & $208=$ & \pm 1.6 & 226 & \pm 6 & 228 & \pm 1.4 & $231 \pm$ & \pm 2 & 151 & 0.021 \\
\hline $\mathrm{Tl}$ & 203 & ${ }^{115} \mathrm{In}$ & $0.697=$ & \pm 0.036 & 0.599 & \pm 0.201 & - & & $0.74 \pm$ & \pm 0.05 & 45 & 0.016 \\
\hline $\mathrm{Tl}$ & 205 & ${ }^{115} \mathrm{In}$ & $0.693=$ & \pm 0.027 & 0.707 & \pm 0.025 & - & & $0.74 \pm$ & \pm 0.05 & 145 & 0.010 \\
\hline V & 51 & ${ }^{103} \mathrm{Rh}$ & $82.4=$ & \pm 5.8 & 112 & \pm 6.2 & 108 & \pm 11 & $112 \pm$ & \pm 5 & 38 & 0.016 \\
\hline $\mathrm{Zn}$ & 66 & ${ }^{72} \mathrm{Ge}$ & 77.1 & \pm 3.6 & 96.8 & \pm 7.6 & 105 & \pm 11 & 106 & \pm 3 & 122 & 0.12 \\
\hline $\mathrm{Zn}$ & 68 & ${ }^{72} \mathrm{Ge}$ & 88.2 & \pm 3.2 & 106 & \pm 6.3 & 106 & \pm 14 & 106 & \pm 3 & 150 & 0.23 \\
\hline
\end{tabular}

Results are given as mean $\pm 95 \%$ confidence interval for 4 separate analyses

Certified values are given as mean $\pm 95 \%$ confidence interval

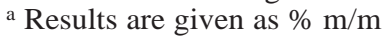

b NIST Information only

» Out of calibration range

- Below detection limit

ng Not given

undiluted), and 10- and 50-fold diluted solutions not only to investigate the efficiency of internal standardization for the correction of the matrix induced suppression, but also to determine the optimum degree of dilution to minimize the suppression. Internal standardization was made with ${ }^{115} \mathrm{In}$ for $\mathrm{Al}, \mathrm{Ba}, \mathrm{Ca}, \mathrm{Eu}, \mathrm{Sr}$ and $\mathrm{Tl}$; with ${ }^{72} \mathrm{Ge}$ for $\mathrm{As}, \mathrm{Co}$, $\mathrm{Cu}, \mathrm{Fe}, \mathrm{Ni}, \mathrm{Se}, \mathrm{Si}, \mathrm{Zn}$ and with ${ }^{103} \mathrm{Rh}$ for $\mathrm{Cd}, \mathrm{Cr}, \mathrm{Hg}, \mathrm{Mg}$, $\mathrm{Mn}, \mathrm{Pb}, \mathrm{Sb}, \mathrm{Sn}$ and $\mathrm{V}$. The results are summarized in
Table 3 together with the instrumental detection limits ( $3 \mathrm{~s}$ ) and blank counts obtained from the original, $6 \% \mathrm{v} / \mathrm{v} \mathrm{HNO}_{3} /$ $3 \% \mathrm{v} / \mathrm{v}$ HF, blank solution. It is clear from the results obtained from the original analysis solutions that the matrix suppression was more pronounced on easily ionizable light elements having $\mathrm{m} / \mathrm{z}$ between $27-88$ a.m.u. except As, Co and Se, which have relatively higher first IPs. The internal standard signals from the reagent blank $\left(6 \% \mathrm{v} / \mathrm{v} \mathrm{HNO}_{3} /\right.$ 
$3 \% \mathrm{v} / \mathrm{v} \mathrm{HF}$ ) and the concentrated sample solutions were used to calculate the magnitude of the total suppression on the ion signals. This suppression varied from 35 to $40 \%$; therefore, the internal standard correction was inaccurate for light elements. On the other hand, the internal standard correction was accurate for heavy elements including $\mathrm{Ba}$, $\mathrm{Cd}, \mathrm{Eu}, \mathrm{Hg}, \mathrm{Pb}, \mathrm{Sn}, \mathrm{Tl}$ and the recoveries varied between 93-105\%. An overcorrection of unknown origin was observed for $\mathrm{Sb}$ when the correction was made with both ${ }^{72} \mathrm{Ge}$ and ${ }^{103} \mathrm{Rh}$. The best results, except for $\mathrm{Al}, \mathrm{Cd}, \mathrm{Cr}, \mathrm{Hg}$ and $\mathrm{Se}$, were obtained from the 10-fold diluted solutions in which the Si concentration varied from 60 to $65 \mu \mathrm{g} / \mathrm{mL}$. The total suppression in ion signals was around $15-18 \%$, and a successful correction was achieved by the internal standards. The results for $\mathrm{Cd}, \mathrm{Hg}$ and $\mathrm{Se}$ were imprecise due to the relatively high detection limits and very low solution concentrations for these elements. In 50-fold diluted solutions, the recoveries of $\mathrm{Al}$ and $\mathrm{Cr}$ were improved by 17 and $15 \%$, respectively, whereas there was no significant increase in the recoveries of other elements. The signals for $\mathrm{As}, \mathrm{Eu}, \mathrm{Sb}, \mathrm{Sn}$ and $\mathrm{Tl}$ were decreased to those obtained with the blank.

An overall evaluation of the data in Table 3 allows the elements to be classified into two groups. The first group includes the elements $\mathrm{As}, \mathrm{Ba}, \mathrm{Cd}, \mathrm{Co}, \mathrm{Eu}, \mathrm{Hg}, \mathrm{Pb}, \mathrm{Sb}, \mathrm{Se}$, $\mathrm{Sn}$ and $\mathrm{Tl}$, for which the assigned internal standards can accurately compensate for the matrix effects; therefore, they can be determined from the concentrated solutions with $90-105 \%$ accuracy despite 35-40\% signal suppression. The second group includes mostly the light elements $\mathrm{Al}, \mathrm{Ca}, \mathrm{Cr}, \mathrm{Cu}, \mathrm{Fe}, \mathrm{Mg}, \mathrm{Mn}, \mathrm{Ni}, \mathrm{Si}, \mathrm{Sr}, \mathrm{V}$ and $\mathrm{Zn}$, for which further dilutions are necessary to decrease the total suppression in the range of $10 \%$ for the accurate correction by the internal standards.

There was no significant interference of ${ }^{40} \mathrm{Ar}^{35} \mathrm{Cl}$ and ${ }^{35} \mathrm{Cl}^{16} \mathrm{O}$ on ${ }^{75} \mathrm{As}$ and ${ }^{51} \mathrm{~V}$, respectively. This was attributed to the very low concentration of chloride in SRM 2709. The ${ }^{42} \mathrm{Ca}$ blank counts were almost an order of magnitude greater than those of ${ }^{44} \mathrm{Ca}$ due to the interference of ${ }^{40} \mathrm{ArH}_{2}$ (Table 3). However, the interference was less significant in sample solutions; therefore, the calcium recoveries from ${ }^{42} \mathrm{Ca}$ were significantly lower than those of ${ }^{44} \mathrm{Ca}$ and the certified value since a greater value of blank signal is always subtracted from that of the analyte.

Cadmium was determined with two most abundant isotopes at m/z 111 and 114 . The isobaric overlap of ${ }^{114} \mathrm{Sn}$ was automatically corrected by the ELAN software. The major polyatomic ion interferences are ${ }^{95} \mathrm{Mo}^{16} \mathrm{O}$ and ${ }^{94} \mathrm{Zr}^{16} \mathrm{OH}$ on ${ }^{111} \mathrm{Cd}$ and ${ }^{98} \mathrm{Mo}^{16} \mathrm{O}$ on ${ }^{114} \mathrm{Cd}[12]$. The NIST information only concentrations for $\mathrm{Mo}$ and $\mathrm{Zr}$ are 2 and $160 \mu \mathrm{g} / \mathrm{g}$, respectively. It has been reported that ${ }^{111} \mathrm{Cd}$ is more prone to interferences in the presence of high $\mathrm{Zr}$ concentration $[12,27]$. However, in our experiments ${ }^{111} \mathrm{Cd}$ provided the most accurate results for SRM 2709 despite the high concentration of $\mathrm{Zr}$. This might be due to either incomplete dissolution of $\mathrm{Zr}$ containing refractory minerals, resulting in negligible numbers of triatomic ${ }^{94} \mathrm{Zr}^{16} \mathrm{OH}$ ions, or an undercorrection for ${ }^{114} \mathrm{Sn}$ interference on ${ }^{114} \mathrm{Cd}$ by the ELAN software, which caused higher ion counts for
${ }^{114} \mathrm{Cd}$. The latter was confirmed by comparing the $\mathrm{Cd} 114$ / 111 isotope ratios obtained from standards and soil solutions with that due to the natural abundances. The natural relative abundance the $\mathrm{Cd} 114 / 111$ ratio is 2.26 . However, the ratio based on the ratio of individual ion counts was always greater: 2.35 for $10 \mu \mathrm{g} / \mathrm{L}$ standard solution and 2.42 for soil solutions. This indicates that an inaccurate correction for ${ }^{114} \mathrm{Sn}$ interference by the ELAN software was the likely source of inaccuracy and uncertainty observed with ${ }^{114} \mathrm{Cd}$ isotope.

Although the certified concentration of $\mathrm{Na}$ in SRM 2709 is high, $1.14 \% \mathrm{~m} / \mathrm{m}$, the interferences of polyatomic ions of ${ }^{40} \mathrm{Ar}^{23} \mathrm{Na},{ }^{40} \mathrm{Ca}^{23} \mathrm{Na}$ were not significant on ${ }^{63} \mathrm{Cu}$ as shown by the signals for ${ }^{65} \mathrm{Cu}$ which is not affected from these interferences. Other possible polyatomic interferences on ${ }^{63} \mathrm{Cu}$ are due to ${ }^{47} \mathrm{Ti}^{160}$ and ${ }^{46} \mathrm{Ti}^{16} \mathrm{H}$, but they were also insignificant.

Three isotopes, ${ }^{77} \mathrm{Se},{ }^{78} \mathrm{Se}$ and ${ }^{82} \mathrm{Se}$, were used for the determination Se. The best results were obtained from ${ }^{77} \mathrm{Se}$ for both reference materials and no significant interference from ${ }^{40} \mathrm{Ar}^{37} \mathrm{Cl}$ was observed. The uncertainty and the magnitude of the support gas interference caused a degradation of both precision and accuracy. Thus, the recoveries of ${ }^{78} \mathrm{Se}$ were lower than that of ${ }^{77} \mathrm{Se}$ due to the interference of ${ }^{40} \mathrm{Ar}^{38} \mathrm{Ar}$ on ${ }^{78} \mathrm{Se}$, which caused higher blank counts and consequently decreased the precision and accuracy. The recoveries of ${ }^{82} \mathrm{Se}$ in the SRM 2709 were significantly lower than those of ${ }^{77} \mathrm{Se}$ and ${ }^{78} \mathrm{Se}$, which was attributed to an overcorrection for the ${ }^{82} \mathrm{Kr}$ overlap by the ELAN software. For low solution concentration of Se (i.e. $10 \mu \mathrm{g} / \mathrm{L}$ ), this effect was more pronounced so that the Se 82/77 counts ratio obtained from a $10 \mu \mathrm{g} / \mathrm{L}$ standard solutions was approximately $40 \%$ lower than that of the natural relative abundances $(\mathrm{Se} 82 / 77=1.21)$. As the Se concentration increased to $30 \mu \mathrm{g} / \mathrm{L}$, the effect of overcorrection was insignificant, and good agreement between for the experimental and theoretical Se 82/77 ratios was obtained.

For the other polyisotopic elements, quantification was based on ${ }^{138} \mathrm{Ba},{ }^{53} \mathrm{Cr},{ }^{153} \mathrm{Eu},{ }^{202} \mathrm{Hg},{ }^{25} \mathrm{Mg},{ }^{60} \mathrm{Ni},{ }^{208} \mathrm{~Pb},{ }^{123} \mathrm{Sb}$, ${ }^{88} \mathrm{Sr},{ }^{120} \mathrm{Sn},{ }^{205} \mathrm{Tl}$ and ${ }^{66} \mathrm{Zn}$, because of the $2-3$ times better precision obtained (RSD $\leq 3 \%)$. However, there were no significant differences in the recoveries of other isotopes.

Determination of trace elements in Fresh Water Plankton (CRM 414)

The same procedure was used for the analysis of the Fresh Water Plankton reference material (CRM 414) for further validation of the methodology for accurate trace element determinations. Complete dissolution was achieved with the $\mathrm{HNO}_{3} / \mathrm{HF}$ microwave-assisted digestion procedure [25]. Aluminium, $\mathrm{Ca}, \mathrm{Cr}, \mathrm{Cu}, \mathrm{Fe}, \mathrm{Mg}, \mathrm{Mn}, \mathrm{Ni}, \mathrm{Si}, \mathrm{Sr}, \mathrm{V}$ and $\mathrm{Zn}$ were determined from 10 -fold diluted solutions while others elements were determined from the original $(50 \mathrm{~mL})$ solutions. The results are summarized in Table 4. In the concentrated solutions, the behavior of the matrix suppres- 
Table 4 Results for CRM 414 (Fresh Water Plankton) obtained with different dilutions
Results are given as mean \pm $95 \%$ confidence interval for 4 separate analyses

Certified values are given as mean $\pm 95 \%$ confidence interval

a Indicative value

${ }^{\mathrm{b}}$ Informative value

${ }^{c}$ Mistake in the unit of the reference value of $\mathrm{Fe}$ ng Not given

\begin{tabular}{|c|c|c|c|c|c|c|}
\hline \multirow{2}{*}{$\begin{array}{l}\text { Element } \\
\mathrm{Al}\end{array}$} & \multirow{2}{*}{$\frac{\text { Isotope }}{27}$} & \multirow{2}{*}{$\begin{array}{l}\text { Internal Standard } \\
{ }^{115} \mathrm{In}\end{array}$} & \multicolumn{2}{|c|}{ Experimental results, $\mu \mathrm{g} / \mathrm{g}$} & \multicolumn{2}{|c|}{ Certified, $\mu \mathrm{g} / \mathrm{g}$} \\
\hline & & & 2752 & \pm 233 & $1800^{\mathrm{b}}$ & \\
\hline As & 75 & ${ }^{72} \mathrm{Ge}$ & $6.69=$ & $\pm \quad 0.62$ & $6.82 \pm$ & \pm 0.28 \\
\hline $\mathrm{Ba}$ & 137 & ${ }^{115} \operatorname{In}$ & $30.8=$ & 1.7 & $31^{\mathrm{b}}$ & \\
\hline $\mathrm{Ba}$ & 138 & ${ }^{115} \mathrm{In}$ & 30.9 & 1.5 & $31^{\mathrm{b}}$ & \\
\hline $\mathrm{Ca}$ & 42 & ${ }^{115} \operatorname{In}$ & 65149 & \pm 1843 & $65000^{\mathrm{b}}$ & \\
\hline $\mathrm{Ca}$ & 44 & ${ }^{115} \mathrm{In}$ & $74338=$ & \pm 2524 & $65000^{\mathrm{b}}$ & \\
\hline $\mathrm{Cd}$ & 111 & ${ }^{103} \mathrm{Rh}$ & $0.376=$ & $\pm \quad 0.031$ & $0.383 \pm$ & \pm 0.014 \\
\hline $\mathrm{Cd}$ & 114 & $103 \mathrm{Rh}$ & $0.356=$ & 0.069 & $0.383 \pm$ & \pm 0.014 \\
\hline Co & 59 & ${ }^{72} \mathrm{Ge}$ & $1.54=$ & 0.11 & 1.43 & \\
\hline $\mathrm{Cr}$ & 52 & ${ }^{103} \mathrm{Rh}$ & 26.2 & 2.0 & $23.8 \pm$ & \pm 1.2 \\
\hline $\mathrm{Cr}$ & 53 & ${ }^{103} \mathrm{Rh}$ & 23.8 & 3.6 & $23.8 \pm$ & \pm 1.2 \\
\hline $\mathrm{Cu}$ & 63 & ${ }^{72} \mathrm{Ge}$ & 24.5 & 1.6 & $29.5 \pm$ & \pm 1.3 \\
\hline $\mathrm{Cu}$ & 65 & ${ }^{72} \mathrm{Ge}$ & 24.9 & 1.2 & 29.5 & \pm 1.3 \\
\hline $\mathrm{Eu}$ & 151 & ${ }^{115} \mathrm{In}$ & $0.021=$ & 0.008 & ng & \\
\hline $\mathrm{Eu}$ & 153 & ${ }^{115} \mathrm{In}$ & $0.016=$ & 0.005 & ng & \\
\hline $\mathrm{Fe}$ & 57 & ${ }^{72} \mathrm{Ge}$ & $1864=$ & 89 & $1850^{\mathrm{b}, \mathrm{c}}$ & \\
\hline $\mathrm{Hg}$ & 200 & ${ }^{103} \mathrm{Rh}$ & $0.303=$ & 0.019 & $0.276 \pm$ & \pm 0.018 \\
\hline $\mathrm{Hg}$ & 202 & ${ }^{103} \mathrm{Rh}$ & $0.304=$ & 0.018 & $0.276 \pm$ & \pm 0.018 \\
\hline $\mathrm{Mg}$ & 25 & ${ }^{103} \mathrm{Rh}$ & $2402=$ & \pm 206 & $2400^{\mathrm{b}}$ & \\
\hline $\mathrm{Mg}$ & 26 & ${ }^{103} \mathrm{Rh}$ & 2430 & \pm 212 & $2400^{\mathrm{b}}$ & \\
\hline Mn & 55 & ${ }^{103} \mathrm{Rh}$ & 282 & $\pm \quad 8$ & 299 & \pm 12 \\
\hline $\mathrm{Ni}$ & 60 & ${ }^{72} \mathrm{Ge}$ & 16.3 & 1.2 & 18.8 & \pm 0.8 \\
\hline $\mathrm{Ni}$ & 61 & ${ }^{72} \mathrm{Ge}$ & 18.8 & 1.7 & $18.8 \pm$ & \pm 0.8 \\
\hline $\mathrm{Ni}$ & 62 & ${ }^{72} \mathrm{Ge}$ & 17.2 & 1.1 & $18.8 \pm$ & \pm 0.8 \\
\hline $\mathrm{Pb}$ & 207 & ${ }^{103} \mathrm{Rh}$ & 3.86 & 0.33 & $3.97 \pm$ & \pm 0.19 \\
\hline $\mathrm{Pb}$ & 208 & ${ }^{103} \mathrm{Rh}$ & $3.84=$ & 0.27 & $3.97 \pm$ & \pm 0.19 \\
\hline $\mathrm{Sb}$ & 121 & ${ }^{103} \mathrm{Rh}$ & $0.099=$ & 0.018 & $0.086^{\mathrm{b}}$ & \\
\hline $\mathrm{Sb}$ & 123 & ${ }^{103} \mathrm{Rh}$ & $0.097=$ & 0.038 & $0.086^{\mathrm{b}}$ & \\
\hline $\mathrm{Se}$ & 77 & ${ }^{72} \mathrm{Ge}$ & $1.65=$ & 0.21 & $1.75 \pm$ & \pm 0.10 \\
\hline $\mathrm{Se}$ & 78 & ${ }^{72} \mathrm{Ge}$ & 1.49 & 0.29 & $1.75 \pm$ & \pm 0.10 \\
\hline $\mathrm{Se}$ & 82 & ${ }^{72} \mathrm{Ge}$ & 1.85 & $\pm \quad 0.15$ & 1.75 & \pm 0.10 \\
\hline $\mathrm{Si}$ & 29 & ${ }^{72} \mathrm{Ge}$ & 13316 & \pm 1356 & ng & \\
\hline Sn & 118 & ${ }^{103} \mathrm{Rh}$ & 1.12 & $\pm \quad 0.29$ & $1.18^{\mathrm{b}}$ & \\
\hline Sn & 120 & ${ }^{103} \mathrm{Rh}$ & 1.16 & 0.34 & $1.18^{\mathrm{b}}$ & \\
\hline $\mathrm{Sr}$ & 86 & ${ }^{115} \mathrm{In}$ & 240 & 5 & $261^{\mathrm{a}}$ & \\
\hline $\mathrm{Sr}$ & 88 & ${ }^{115} \operatorname{In}$ & $242=$ & 11 & $261^{\mathrm{a}}$ & \\
\hline $\mathrm{Tl}$ & 203 & ${ }^{115} \mathrm{In}$ & $0.037=$ & 0.007 & $0.047^{\mathrm{b}}$ & \\
\hline $\mathrm{Tl}$ & 205 & ${ }^{115} \mathrm{In}$ & $0.029=$ & 0.007 & $0.047^{\mathrm{b}}$ & \\
\hline V & 51 & ${ }^{103} \mathrm{Rh}$ & $9.48=$ & 0.340 & $8.10 \pm$ & \pm 0.18 \\
\hline $\mathrm{Zn}$ & 66 & ${ }^{72} \mathrm{Ge}$ & $101=$ & 5 & $112=$ & \pm 3 \\
\hline $\mathrm{Zn}$ & 68 & ${ }^{72} \mathrm{Ge}$ & 103 & 8 & 112 & \pm 3 \\
\hline
\end{tabular}

sion on light elements was very similar to that which occurred in the analysis of the soil reference material. However, due to the low concentration of $\mathrm{Si}$ in comparison to that in the soil, the suppression was completely eliminated by 10 -fold dilution and good agreement was obtained with the certified values. A discrepancy of approximately $50 \%$ was found between the "informative" and the measured concentration of $\mathrm{Al}$. Although the result for ${ }^{42} \mathrm{Ca}$ is very close to the informative value, the result from the ${ }^{44} \mathrm{Ca}$ isotope was considered to be more reliable due to the inaccurate result for the former in the soil. The behaviors of ${ }^{111} \mathrm{Cd}$ and ${ }^{114} \mathrm{Cd}$ isotopes were similar to those observed for the soil, and ${ }^{111} \mathrm{Cd}$ again provided the most accurate result. An error was found in the units of the indicative value of $\mathrm{Fe}$, which was reported as $1.85 \mu \mathrm{g} / \mathrm{g}$ by BCR. The same reference material was analyzed by Pettersson et al. [28] by total-reflection X-ray fluorescence spectrometry for determination of the trace elements including $\mathrm{Fe}$, and a similar error was also reported for the Fe concentration unit. Unlike the soil, the results for the ${ }^{77} \mathrm{Se}$ and ${ }^{82} \mathrm{Se}$ isotopes were very similar and agreed with the certified value. This may be due to the higher concentration of Se in the CRM 414.

Analysis of marine plankton samples

Aluminium, $\mathrm{Ca}, \mathrm{Cr}, \mathrm{Cu}, \mathrm{Fe}, \mathrm{Mg}, \mathrm{Mn}, \mathrm{Ni}, \mathrm{Sr}, \mathrm{V}$ and $\mathrm{Zn}$ were determined from 10-fold diluted solutions, while the other elements were determined from the original $50-\mathrm{mL}$ solutions. The results for the regular plankton $(3 \mathrm{H}-32$ and $3 \mathrm{H}-$ 
Fig. 2 The effect of macronutrients $(\mathrm{Cr}, \mathrm{Zn})$ on the bioavailability of potentially toxic elements ( $\mathrm{Cd}, \mathrm{Co}, \mathrm{Hg}, \mathrm{Pb}$, and $\mathrm{V}$ ) in the absence of Se to plankton (3H-32 plankton samples)

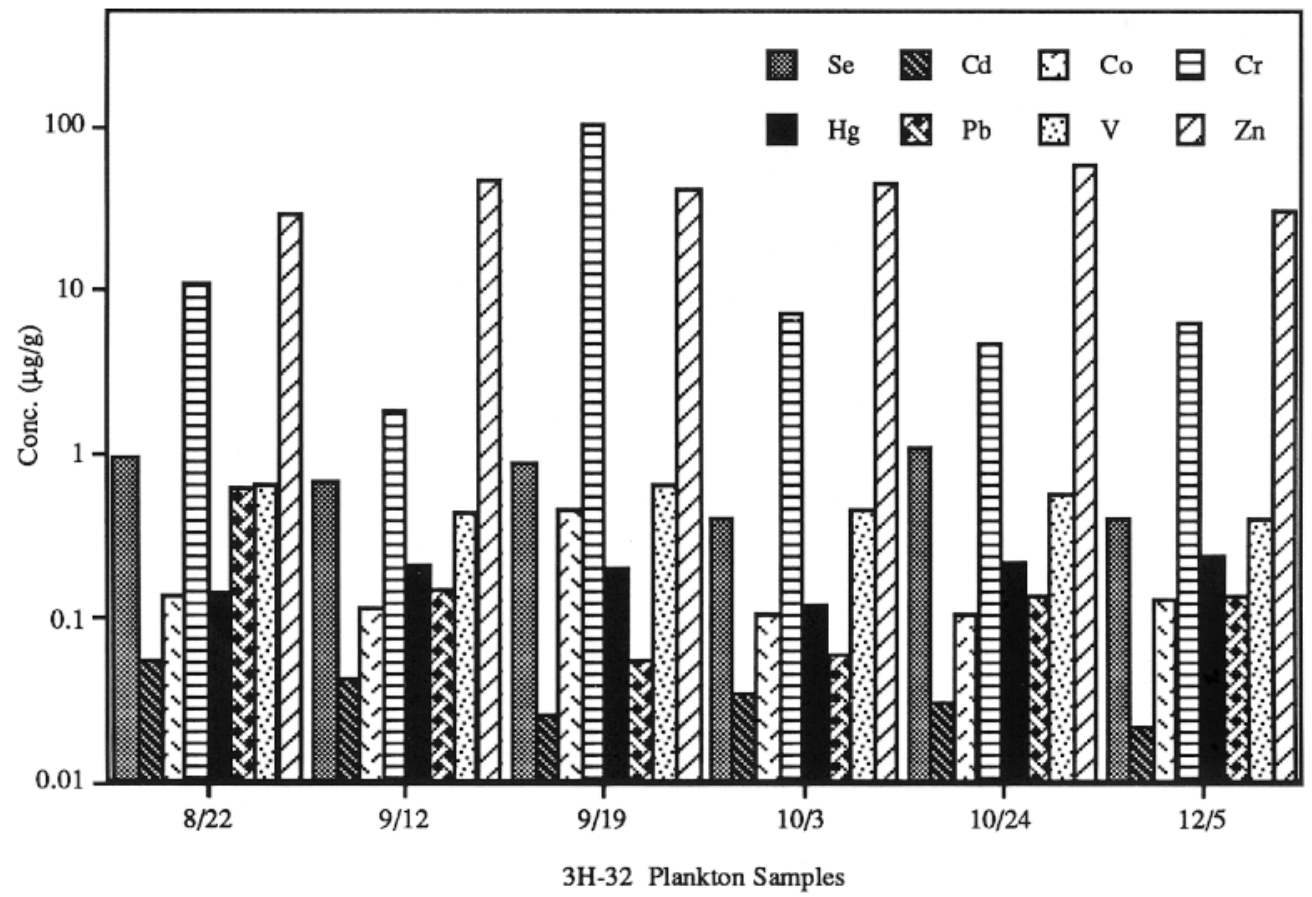

34) and the Se-enriched (3H-33) plankton samples are summarized in Tables 5 and 6, respectively (available as supplementary electronic material). The signal suppression behavior was very similar to that observed for the soil, which was eliminated by 10 -fold dilution. Since As, Ba, Cd, $\mathrm{Co}, \mathrm{Eu}, \mathrm{Hg}, \mathrm{Pb}, \mathrm{Sb}$ and $\mathrm{Tl}$ were present at very low concentrations, the results for these elements from the analysis of diluted solutions were erratic due to the reagent blanks.

Although no Se was added into the growth medium of $3 \mathrm{H}-32$ and $3 \mathrm{H}-34$ plankton samples, Se was found to be present in these samples. The concentrations of Se in the $3 \mathrm{H}-32$ samples were very low as expected. However, $3 \mathrm{H}-$ 34 samples contain significant amounts of Se. Thus, in contrast to the results of $3 \mathrm{H}-32$ plankton samples, the results of the ${ }^{77} \mathrm{Se},{ }^{78} \mathrm{Se}$ and ${ }^{82} \mathrm{Se}$ isotopes were $5-6$ times more precise (RSD $\leq 3 \%)$. Semi-quantitative analysis of the plankton solutions gave a $\mathrm{Na}$ concentration of between 1500 and $2000 \mu \mathrm{g} / \mathrm{mL}$. Even though this suggests that a high concentration of chloride is present equal to that of $\mathrm{Na}$, the agreement among the ${ }^{77} \mathrm{Se},{ }^{78} \mathrm{Se}$ and ${ }^{82} \mathrm{Se}$ results indicates that the interference of ${ }^{40} \mathrm{Ar}^{37} \mathrm{Cl}$ on ${ }^{77} \mathrm{Se}$ was insignificant.

It can be seen that $\mathrm{Si}$ constitutes the majority of the plankton together with $\mathrm{Al}, \mathrm{Ca}, \mathrm{Cu}, \mathrm{Fe}, \mathrm{Mg}, \mathrm{Mn}$ and $\mathrm{Zn}$ as the other major elements. The concentrations of Al, especially in 3H-32 samples, were significantly greater than the expected value $(50 \mu \mathrm{g} / \mathrm{g})$, which might be due to the additional uptake of $\mathrm{Al}$ from the seawater. The concentrations of $\mathrm{Al}, \mathrm{Ca}, \mathrm{Cu}$ and $\mathrm{Zn}$ (except in sample 3/27) in $3 \mathrm{H}-34$ samples were 2 to 3 times lower than those of the $3 \mathrm{H}-32$ samples. This is attributed to the higher Se concentration of the $3 \mathrm{H}-34$ samples, which might be preferentially taken up by the plankton. In the determination of $\mathrm{Cu}$, the high $\mathrm{Na}$ concentration caused a significant difference between the
${ }^{63} \mathrm{Cu}$ and ${ }^{65} \mathrm{Cu}$ results, since the former isotope suffers from the interference of ${ }^{40} \mathrm{Ar}^{23} \mathrm{Na}$, the ${ }^{65} \mathrm{Cu}$ results were considered to be more accurate.

Culture studies have illustrated that the uptake of potentially toxic elements is in competitive interaction with the concentrations of micronutrient elements to maintain the growth rate [28-30]. Price and Morel [29] reported that the addition of $\mathrm{Cd}$ (or $\mathrm{Co}$ ) to $\mathrm{Zn}$-free media stimulated the growth rates to near maximal levels for a coastal phytoplankton (diatom) culture. In a similar study, Sunda and Huntsman [30] reported that $\mathrm{Co}$ and $\mathrm{Zn}$ replaced one another metabolically and the cellular Co uptake increased 700-fold with decreasing $\mathrm{Zn}$ concentration in the growth of marine plankton. In the $3 \mathrm{H}$ study, the low concentrations of $\mathrm{Cd}$ and $\mathrm{Co}$ were in good agreement with these previous findings, namely that the uptake of $\mathrm{Cd}$ and $\mathrm{Co}$, which are toxic at high concentrations, is controlled by the availability of $\mathrm{Zn}$ (Fig. 2). Gonzales-Davilla et al. [31] reported that the adsorption of $\mathrm{Pb}$ to the cell surface in the phytoplankton Dunaliella tertiolecta decreased with the decreasing temperature and salinity, and was suppressed by presence of $\mathrm{Cu}$. However, despite the low concentrations of $\mathrm{Cu}$ in 3H-34 samples, there was no significant evidence for a subsequent increase in $\mathrm{Pb}$ concentration. However, the presence of Se in the medium could be another factor limiting the uptake of $\mathrm{Pb}$.

A significant increase in the $\mathrm{Hg}$ concentration was observed in the 3H-34 3/27/97 and 5/1/97 samples. This effect was more pronounced for Se-enriched plankton samples that the concentration of $\mathrm{Hg}$ was higher by a factor of 4 5 times than those obtained from $3 \mathrm{H}-32$ plankton samples (Figs. 2 and 3). Ganther et al. [32] found that for tuna fish an increase in Se concentration decreased the toxicity of methylmercury. Thus, it may be argued that plankton can 
Fig. 3 The effect of Se on the planktonic uptake of $\mathrm{Cd}$, $\mathrm{Co}$, $\mathrm{Cr}, \mathrm{Hg}, \mathrm{Pb}, \mathrm{V}$ and $\mathrm{Zn}(3 \mathrm{H} \mathrm{Se}-$ enriched plankton samples)

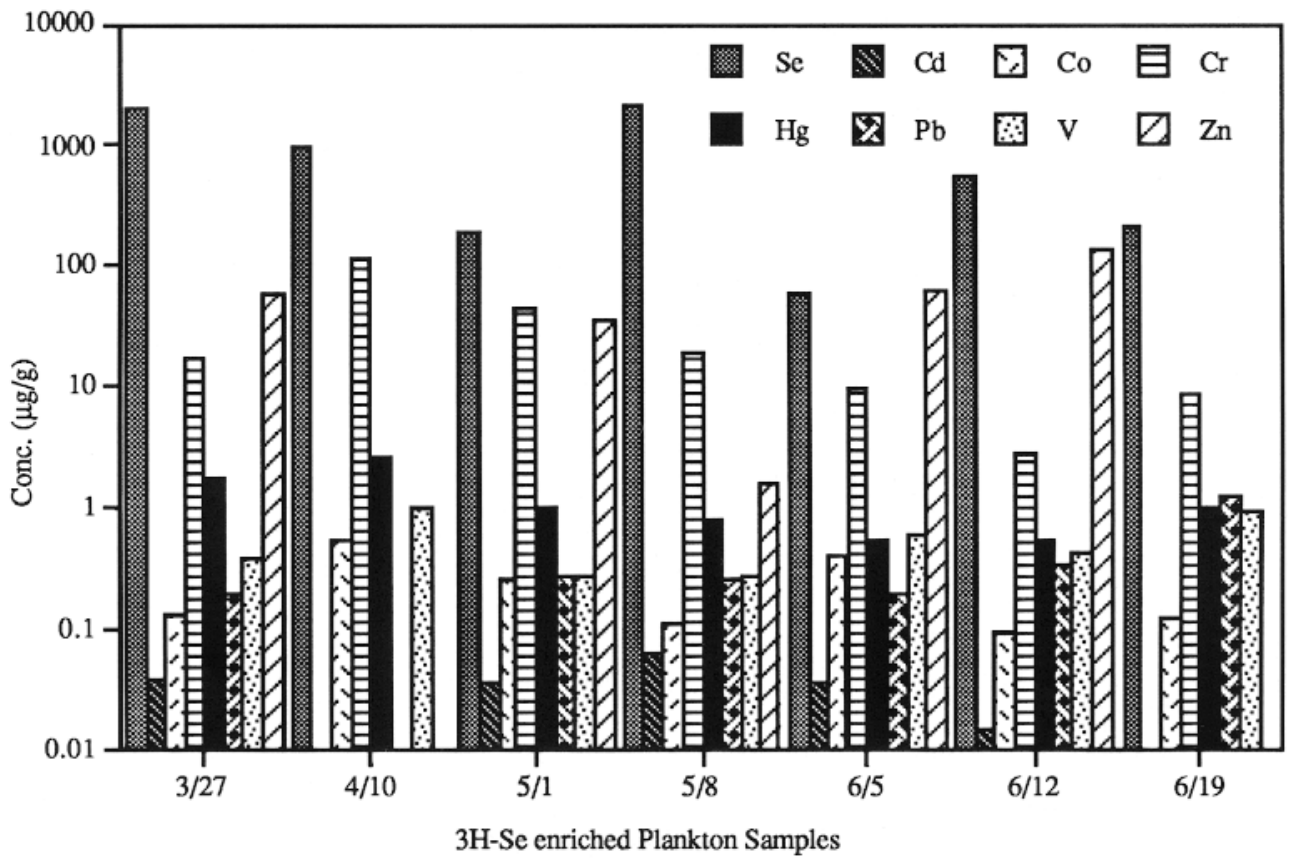

support for Nusret Ertas, and the Perkin Elmer Corporation (Norwalk, CT) for the provision of the Elan 5000 ICP-MS during the course of this study. This paper is funded in part by a grant from the National Oceanic and Atmospheric Administration (NOAA). The views expressed herein are those of the authors and do not necessarily reflect the views of NOAA or any of its sub-agencies.

\section{References}

1. Newell GE, Newell RC (1973) Marine Plankton: A practical guide. Hutchinson, London, p 32-40

2. Nybakken, JW (1988) Marine Biology: An ecological approach. 2nd Ed, Harper and Row, New York, p 46-52

3. Geiger W, Gachter R (1979) Schwiez Z Hydrol 41:277-289

4. Sorentino C (1979) Phyhos 18:149-161

5. Reinfelder JR, Fisher NS (1994) Limnol Oceanogr 39:12-20

6. Quevauviller P, Vercoutere K, Muntau H, Griepink B (1993) Fresenius J Anal Chem 345:12-17

7. Subrahmanyam MNV, Ananthalakshmi Kumari KVV (1990) Indian J Mar Sci 19:177-180

8. Evans EH, Giglio JJ (1993) J Anal At Spectrom 8:1-18

9. Hieftje GM, Myers DP, Li G, Mahoney PP, Burgoyne TW, Ray SJ, Guzowski JP (1997) J Anal At Spectrom 12:287-292

10. Moens L (1997) Fresenius J Anal Chem 359:309-316

11. Vandecasteele C, Vanhoe H, Dams R (1993) J Anal At Spectrom 8:781-786

12. Wu S, Zhao Y, Feng X, Wittmeier A (1996) J Anal At Spectrom 11:287-296

13. Sakao S, Ogawa Y, Uchida H (1997) Anal Chim Acta 355: 121-127

14. Stroh A, Brückner P, Völlkopf U (1994) Atomic Spectroscopy 15:100-106

15.Zhou H, Liu J (1997) Atomic Spectroscopy 18:115-118

16. Bettinelli M, Baroni U (1995) Atomic Spectroscopy 16:203210

17. Alaimo R, Censi P (1992) Atomic Spectroscopy 13:113-117

18. Falk H, Geerling R, Hattendorf B, Krengel-Rothensee K, Schmidt KP (1997) Fresenius J Anal Chem 359:352-356

19. Moens L, Verrept P, Dams R, Greb U, Jung G, Laser B (1994) J Anal At Spectrom 9:1075-1083
Acknowledgements The authors gratefully acknowledge Marmara University (Turkey) for financial support for Zikri Arslan, the Scientific and Technical Research Council of Turkey for financial 
20. Stroh A, Völlkopf U, Deyoner ER (1992) J Anal At Spectrom 7:1201-1205

21. Deyoner ER, Stroh A, Lu Q (1993) Atomic Spectroscopy 14: 55-59

22. Maher W, Deaker M (1997) Talanta 350:287-294

23. Haswell SJ, Razagui IB-A (1997) J Anal Toxicol 21:149-153

24. Langmyhr FJ, Sveen S (1965) Anal Chim Acta 32:1-7

25. Arslan Z, Tyson JF (1999) Talanta (in press)

26. Hoenig M, Baeten H, Vanhentenrijk S, Vassileva E, Ouevauviller Ph (1998) Anal Chim Acta 358:85-94

27. Cook JM, Robinson JJ, Chenery SRN, Miles DL (1997) Analyst 122:1207-1210
28. Pettersson RP, Olsson M (1998) J Anal At Spectrom 13:609613

29. Price NM, Morel FMM (1990) Nature 344:658-660

30. Sunda WG, Huntsman SA (1995) Limnol Oceanogr 40:14041417

31. Santana-Casiano JM, Gozales-Davilla M (1995) Mar Chem 418:115-129

32. Ganther HE, Goudie C, Sunde ML, Kopecky MJ, Wagner P, Oh S-H, Hoekstra WG (1972) Science 175:1122-1124

33. Nichols GD, Curl H, Bowen VT (1959) Limnol Oceanogr 4: $472-478$ 